\title{
Fostering safe vascular access for adolescents during hemodialysis using cushion cannulation versus common cannulation techniques
}

\author{
Orban Ragab Bayoumi Ibrahim ${ }^{1}$, Sahar Mahmoud El-Khedr Abd El-Gawad *2 \\ ${ }^{1}$ Pediatric Nursing Department, Faculty of Nursing, Ain shams University, Egypt \\ ${ }^{2}$ Pediatric Nursing Department, Faculty of Nursing, Tanta University, Tanta, Egypt
}

\author{
Received: October 13, 2016 \\ Accepted: January 6, 2017 \\ Online Published: February 9, 2017 \\ DOI: $10.5430 /$ jnep.v7n7p1 \\ URL: http://dx.doi.org/10.5430/jnep.v7n7p1
}

\begin{abstract}
Background and objective: Chronic hemodialysis is technically feasible in children of all ages. Vascular access is a hemodialysis patient's lifeline, and successful cannulation is critical to the viability of the vascular access. Common and cushion cannulation techniques can be used by the nurses during cannulation of the patients. However, it is not known which approach is most effective. This study aimed to foster safe vascular access for adolescents during hemodialysis using cushion cannulation versus common cannulation techniques.

Methods: Study design: A quasi-experimental study was used. Setting: The study was conducted at Hemodialysis Units affiliated to King Abdullah Bin Abdul-Aziz Al Saud International Foundation Dialysis Care Center at Jeddah. Subjects: A purposive sample composed of 60 adolescents undergoing hemodialysis and 60 nurses "whom providing care for those adolescents were involved in this study". Tools: Four tools were used namely; Structured Questionnaire Sheets, Observation Sheet, Adolescents and nurses' opinion about cushion and common cannulation techniques, and Pain Assessment Scale.

Results: The majority of adolescents felt that using the cushion cannulation technique was more comfortable position. Also, most nurses mentioned that using the cushion technique improves body mechanics and promotes easy access to fistula.

Conclusions: The current study concluded that, using cushion technique was associated with safe vascular access for adolescents during hemodialysis, it also stabilizes the arm and tissues and fully extension of the arm. Negative correlation was observed between cushion technique safety and numeric pain scale. Meanwhile, there was insignificant positive correlation using common cannulation technique and numeric pain scale. Recommendations: Application of the cushion technique in HD centers as part of a routine care for all patients undergoing hemodialysis therapy, and implement in-service training programs related to the cushion technique for all nurses working in Hemodialysis Units.
\end{abstract}

Key Words: Adolescents, Nurses, Hemodialysis, Safe vascular access, Cushion cannulation, Common cannulation technique

\section{INTRODUCTION}

Adolescents with serious renal disease are a vulnerable group of patients. Those who have history of significant renal disease from early childhood may have delayed physiological and psychosocial development, academic disadvantage and diminished self-esteem. Furthermore, coping with renal failure and hemodialysis (HD) sessions lasting an average of four hours, three times a week, tends to lead to social isola-

\footnotetext{
* Correspondence: Sahar Mahmoud El-Khedr Abd El-Gawad; Email: sahar.khedr@yahoo.com; Address: Pediatric Nursing Department, Faculty of Nursing, Tanta University, Tanta, Egypt. 
tion. ${ }^{[1]}$

The prevalence of acute and chronic Renal Failure (CRF) is high in the Arab world. The reported prevalence of CRF is 80 to 120 per million population (pmp) in Saudi Arabia and 225 pmp in Egypt. In Europe it is estimated to be $283 \mathrm{pmp}$ 957 in the United States and 1.149 pmp in Japan. ${ }^{[1]}$ In Saudi Arabia, the prevalence and incidence of end stage chronic kidney disease in children $\leq 15$ years are estimated to be 16.4 and 4.76 pmp respectively. Also, it was reported to be 325.22 and 94.46 pmp respectively for children aged 16-25 years. $^{[2,3]}$

An estimate that three to five adolescents pmp develop chronic renal failure annually, where $70 \%$ of them require dialysis for short periods and $23 \%$ require prolonged HD support. ${ }^{[4]}$ There are three access types for hemodialysis; Arteriovenous (AV) fistula, AV graft and central venous catheter. Provision of adequate vascular access remains the single greatest obstacle to successful HD. So, effective safe vascular access is one of the most important factor for successful HD. ${ }^{[5,6]}$

Preparation of the needle sites is probably the most important aspect of cannulation. To minimize the possibility of infections, nurses caring for patients undergoing HD must identify the different steps with regard to basic safety of needle cannulation. These steps include: Identifying the type of access, the direction of blood flow and adjusting the patients' position during HD. It is necessary that vascular accesses should be evaluated prior to every cannulation using these three aspects of nursing care. ${ }^{[7-9]}$

Common and cushion cannulation techniques can be used by the nurses during cannulation of the patients. During common cannulation technique, the patients extend the arm to a 90 degree angle, in patients with rolling and retracting blood vessels in order to make cannulation easier to achieve. Extending the limb is successful because the arm has been inadvertently placed in the surgical position. The typical position for cannulation is with the patient's arm somewhat parallel to the body as the patient sits in the chair with patient's arm on the arm rest. ${ }^{[10]}$

When the arm is down, close to the body, which is a common cannulation position, an upper arm fistula may have as much as one-third of the usable length masked by the chest wall. This concentrates cannulation sites in a smaller portion of the access area, creating the potential for decreased life-span expectancy for access at that site. Alternatively, the patient may extend the access arm while in sitting position or supine position without supporting the arm. However, in this tech- nique the patient is more able to pull back their arm during cannulation. $^{[11]}$

During cushion cannulation technique, the patient extends the access arm to the side horizontally at or just below shoulder level, and rests it on the cushion. The cushion is then positioned as far as possible supporting elbow joint. ${ }^{[5]}$ Placing the arm in the extended or the surgical position allow the nurse to be able to cannulate and access more successfully. This position provides a solid base from which to cannulate the blood vessels in the access area, making it less likely that the blood vessels will roll or retract as in the 90-degree position. This limiting of the fistula's or graft's ability to move or "roll" makes cannulation much more successful. With the use of the cushion technique, the arm can be easily extended and supported, which will stretch and expose the entire usable length of the fistula, so the patient should feel more comfortable during cannulation. ${ }^{[12]}$

Improving vascular access outcomes by the nurse can result in great improvement in access longevity. The use of proper positioning of the arm using cushion cannulation, may increase vascular access life expectancy, so, patients and cannulators comfort will be enhanced. ${ }^{[7]}$ Educating patients in the basic vascular access care such as: how to compress a bleeding access, wash skin over access with soap and water daily and before HD, recognize signs and symptoms of infection, palpate for thrill/pulse daily and avoid carrying heavy items draped over the access arm or wearing occlusive clothing, avoid sleeping on the access arm. The nurse rotates cannulation sites at each treatment, ensures that proper technique is used to prepare the skin prior to cannulation and report any signs and symptoms of infection or absence of bruit/thrill. ${ }^{[13]}$

\subsection{Significance of the study}

Vascular access is a hemodialysis patient's lifeline, and successful cannulation is critical to its viability. One of the best ways to preserve the access is to decrease cannulation attempts and needle manipulation. This will lessen the chance of infiltration and damage to the vessel wall of the VA. Multiple needle sticks increase the probability of vessel damage due to the development of aneurisms, infiltrations, and vessel lining damage. Provision of adequate vascular access remains the single greatest obstacle to successful $\mathrm{HD}$; hence, it is crucial to use a strategy to prolong the viability of vascular access. The researchers in the current study try to use the cushion cannulation technique instead of the common technique for safe vascular access and for successful hemodialysis. There is a limitation of research in this area of practice. 


\subsection{Aim of the study}

The aim of this study was to foster safe vascular access for adolescents during hemodialysis using cushion cannulation versus common cannulation techniques.

\subsection{Research hypothesis}

The current study hypothesized that

(1) Both cushion and common cannulation techniques are similar regarding safe vascular access during hemodialysis.

(2) There is a difference regarding insertion techniques using cushion and common cannulation techniques from both adolescents and nurses' opinions on comfort, confidence and easy implementation.

\section{SUBJECTS AND METHODS}

\subsection{Research design}

A quasi experimental study was utilized.

\subsection{Research setting}

The study was conducted at Hemodialysis Units affiliated to King Abdullah Bin Abdul-Aziz International Foundation Dialysis Care Center at Jeddah.

\subsection{Research subjects}

A purposive sample composed of 60 adolescents undergoing hemodialysis therapy and 60 nurses who provide care for those adolescents in the selected setting. Adolescents were selected according to certain inclusive and exclusive criteria.

\subsection{Inclusion criteria for adolescents patients}

- Patients aged from 12-20 years;

- Both genders;

- Had hemodialysis $\geq$ one year;

- AVF upper arm;

- Free from AV access complications.

\subsection{Exclusion criteria for adolescents patients}

- Patients who have any other diseases (e.g. hepatitis, AIDs... );

- Newly diagnosed patients.

\subsection{Tools of data collection}

Data were collected through using the following tools.

\section{Tool (I): Structured questionnaire sheet}

A structured questionnaire sheet was developed by the researchers to collect demographic data about the study sample and assess adolescents' knowledge about AV access safe. It consisted of two parts:
Part (1): Concerned with the following:

(1) Demographic data of adolescents, such as age, gender.

(2) Assessment of adolescents' knowledge about safe vascular access. Time taken to complete the questionnaire ranged from 10-15 minutes.

Scoring system: Adolescents' knowledge questionnaire regarding AV access safe consisted of 8 items. "Yes" answer scored one and "no" answer scored zero. Accordingly, adolescents' responses were classified into either correct $(>50 \%)$ or incorrect knowledge $(<50 \%)$.

Part (2): Nurses socio-demographic data including age, years of experience in HD.

\section{Tool (II): Observation sheet}

An observation sheet was adopted from Brower (2005) ${ }^{[8]}$ and Ball (2006) ${ }^{[14]}$ and was used by the researchers to assess routine performance of nurses during hemodialysis session using the common cannulation technique. Time taken for filling the sheet ranged between 15-20 minutes for each nurse. Nurses' performance was observed during preparation of procedure and termination of cannulation. It was consisted of 7 steps concerned with patient's positioning, examination of AVF, extending the HD arm, identifying the inflow and outflow rate, cannulation technique and beginning the dialysis session. The nurses performance scored, not done scored "zero" and done scored " 1 ".

Tool (III): A questionnaire adapted from Mott and Prowant(2006) ${ }^{[12]}$ and Ball (2006) ${ }^{[14]}$

It was modified, translated into Arabic language and tested for validity and reliability. It was used by both adolescents and nurses, to assess their opinion about cushion and common techniques. The questionnaire scored as yes " 1 " or no "zero". Time taken for completion of this part was ranged between 10-15 minutes. It was consisted of two parts:

Part (1): Adolescents' opinion about both techniques. It was consisted of five statements concerned with comfort in position, stabilization and extension of arm, pull back during cannulation and safe technique.

Part (2): Nurses' opinion about the two techniques. It was involved six statements concerned with opinion about body mechanics, easily access, stability of hand, shadow from bending over the access, proper eye level, and determination of angle.

\section{Tool (IV): Pain assessment scale}

It was used to assess the adolescents' level of pain during common and cushion cannulation techniques. It included Numeric Pain Intensity Scale, that was adopted from Galer and Gammaitoni (2003). ${ }^{[15]}$ The scale consists of a single $10 \mathrm{~cm}$ 
horizontal line with numerical 0-10 numbered points, ranged from no pain to the worst possible pain. The adolescents were asked to select numbers that resemble their sensation of pain. It was ranged from (zero no pain) (1-3 mild) (4-7 moderate) (8-10 severe) (see Figure 1).

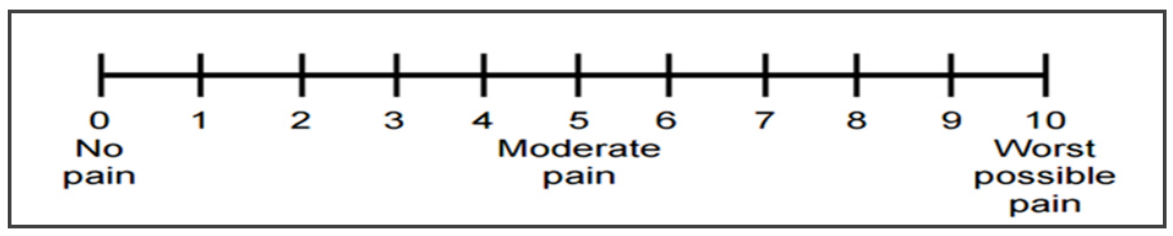

Figure 1. Numeric Pain Intensity Scale

\subsection{Preparatory phase}

A review of historical and current national and international literature related to all aspects of the study was done in order to be acquainted with the research problem and to develop the study tools.

\subsection{Pilot study}

A pilot study was conducted on $10 \%$ of the full sample (6 patients and 6 nurses) in order to test the clarity, feasibility, applicability, content validity of the tools and time required to complete the study tools. Based on the results of this pilot study, all necessary adjustments were made prior to the commencement of the main study from which the participants in the pilot study were excluded.

\subsection{Validity and reliability}

The tools for the collection of data were reviewed by five experts in the field and their validity and reliability tested using Cronbach's alpha. Results were 0.812 for knowledge, 0.773 for opinion, 0.842 for the cushion cannulation technique and 0.72 for the common cannulation technique.

\subsection{Field work}

Data were collected from October 2015 until the end of December 2015. Researchers handled about three patients per day and were available for 3 days per week in different shifts. The nature and the purpose of the study were explained to the nurses and adolescents during the initial interview. Data were collected through interviewing and a direct observation method. Common and cushion cannulation techniques were applied by the nurses to the participating adolescents. First: Common cannulation technique that was routinely applied by the nurses (pretest). Second: Cushion cannulation technique as a new technique applied by the nurses after explanation of how to apply this technique by the researchers for the same participating adolescents (posttest).

\subsection{Procedures}

Adolescent patients attended for hemodialysis sessions three days per week at which time the researchers simultaneously conducted the study.

\section{Start of the first week of data collection (first session of research)}

The researchers collected socio-demographic characteristics of adolescents and nurses. Adolescents' knowledge about AV access safety was assessed using a structured questionnaire sheet. Also, the performance of nurses executing the common cannulation technique was observed throughout hemodialysis sessions and recorded using the observation sheet.

\section{Second session}

Pretest was completed for adolescents during the common cannulation technique that was routinely used by the nurses, and adolescent's pain was assessed using a numerical pain scale at the end of the first week, this means after three consecutive hemodialysis sessions.

\section{Start of the second week (third session)}

The nurses applied the cushion cannulation technique to the same group of adolescents, each of whom was fully informed about the importance and benefits of the cushion. The cushion technique was applied by the nurses at the beginning of a hemodialysis session using the following steps:

(1) The adolescent in a sitting position extends the access arm resting it horizontally on the cushion;

(2) The cushion is positioned as far as possible up and under the patient's armpit with the arm help straight on the cushion;

(3) The nurse then initiates cannulation and begins dialysis session.

\section{Fourth session}

Posttest was done using adolescents and nurses opinion questionnaires and the pain assessment scale. This was done after three consecutive hemodialysis sessions of applying the cushion cannulation technique. Consequently, adolescents and nurses could judge and compare the common and cushions cannulation techniques after three hemodialysis sessions. 


\subsection{Statistical analysis}

The statistical package SPSS (ver. 17) was used to analyze the data of the study. The data were coded, analyzed and standard descriptive statistics were calculated. Tests of significance were done and correlations were calculated between essential parameters. Tests of reliability were done using Cronbach's alpha.

\subsection{Ethical considerations}

Official permission was obtained before the collection of data commenced. Also verbal consent from each adolescent patient was obtained before conducting the study. The nature of the study and its expected outcomes were explained to each participant, and each was informed that they had the right to withdraw from the study at any time without penalty.

\section{RESUlts}

Figure 2 illustrates that $64 \%$ of the adolescents were aged $18: \leq 20$ years and only $3 \%$ were aged $12:<14$ years. The mean age of adolescents was $17.65 \pm 1.64$ years.

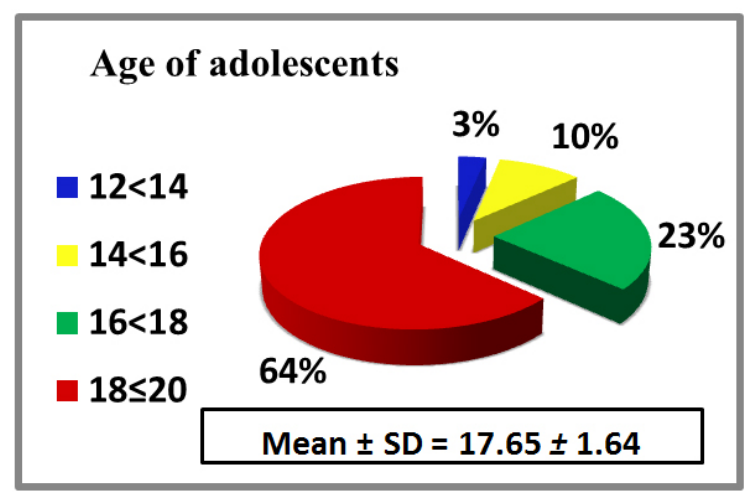

Figure 2. Percent distribution of adolescents according to their age

Figure 3 indicates that $51.7 \%$ of the adolescents were male and $48.3 \%$ were female.

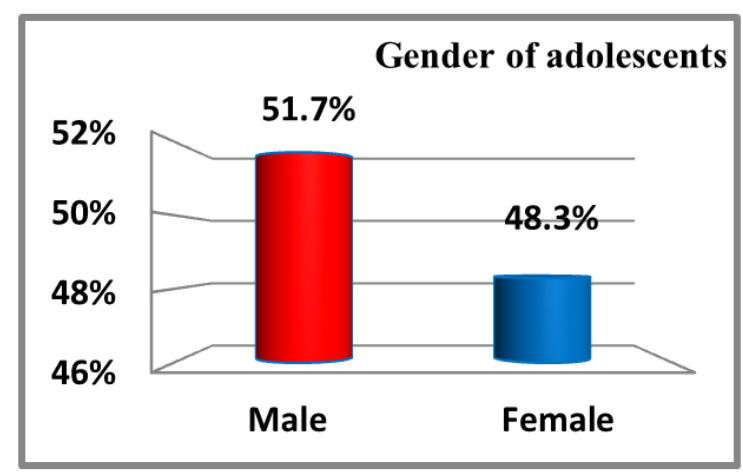

Figure 3. Percent distribution of adolescents according to their gender
Figure 4 illustrates that $57 \%$ of the nurses were aged $25:<$ 30 years with mean age of $26.66 \pm 4.07$ years.

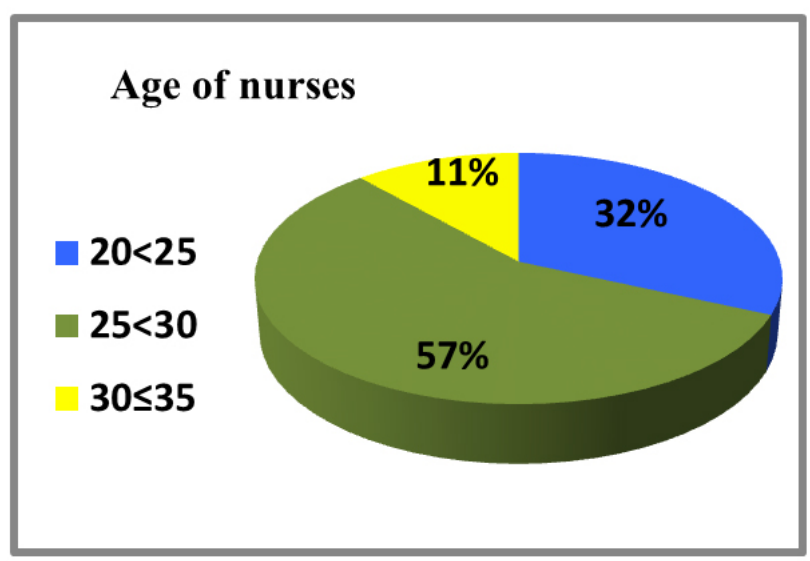

Figure 4. Percent distribution of nurses according to their age $($ no. $=60)$

Figure 5 illustrates that $41 \%$ of nurses had $3:<6$ years of experience, while $40 \%$ of them had $1:<3$ years of experience.

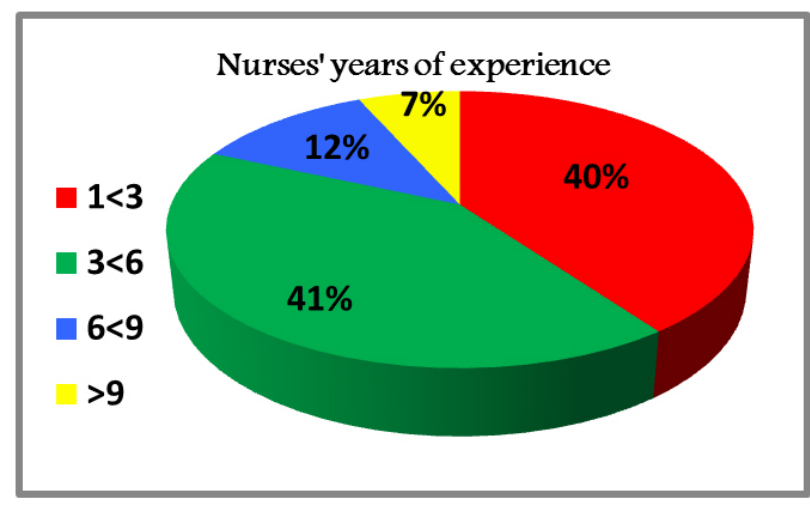

Figure 5. Percent distribution of nurses according to their years of experience

Table 1 illustrates that all adolescents had correct knowledge about AVA safety in the form of: keeping the access site clean, not wearing clothes that restrict access to the site, not using the arm with AV fistula to carry heavy object. Also $91.7 \%$ of adolescents prevented anyone measuring blood pressure using arm with AV access site. Roughly half $(51.7 \%)$ of adolescents were knowledgeable about monitoring the access site for signs of infection, but had incorrect knowledge about palpating the access site for vibrations to check the functioning of the access. Furthermore, Table 1 indicates that there was a statistical significant difference regarding prevention of using the AV access arm for measuring BP and not sleeping on the arm with vascular access.

Table 2 indicates that $56.7 \%$ of nurses did not assist patients in the sitting position, while all palpate AVF for thrill after 
skin penetration, extend patient's arm, initiate cannulation technique and begin dialysis session. It was observed that $40 \%$ of nurses did not pull the skin over the cannulation site.
Also, a statistical significant difference was found regarding their ability to differentiate between inflow and outflow ( $p<$ $.001)$.

Table 1. Percent distribution of adolescents' knowledge about arterio-venous access (AVA) safety $($ no. $=60)$

\begin{tabular}{|c|c|c|c|c|c|c|}
\hline \multirow{2}{*}{ Adolescents' Knowledge } & \multicolumn{2}{|c|}{ Correct Knowledge } & \multicolumn{2}{|c|}{ Incorrect Knowledge } & \multirow{2}{*}{$\chi^{2}$} & \multirow{2}{*}{$p$} \\
\hline & no. & $\%$ & no. & $\%$ & & \\
\hline Palpate the access site. & 29 & 48.3 & 31 & 51.7 & .267 & .606 \\
\hline Monitor for signs of infection. & 31 & 51.7 & 29 & 48.3 & .000 & 1.000 \\
\hline Keep the access site clean. & 60 & 100 & 0 & 0 & 0 & 1 \\
\hline Don't wear restrict clothes. & 60 & 100 & 0 & 0 & 0 & 1 \\
\hline Prevent anyone to use the AVF extremity for obtaining BP. & 55 & 91.7 & 5 & 8.3 & 38.40 & $.000^{*}$ \\
\hline Not to carry heavy object with arm. & 60 & 100 & 0 & 0 & 0 & 1 \\
\hline Don't sleep on AVF arm. & 57 & 95 & 3 & 5 & 45.06 & $.000^{*}$ \\
\hline Not applying cream and lotion on the site of vascular access. & 27 & 45 & 33 & 55 & 1.06 & .302 \\
\hline
\end{tabular}

$* p$-value was considered significant at .001 .

Table 2. Percent distribution of routine performance of nurses during hemodialysis session (no. $=60$ )

\begin{tabular}{|c|c|c|c|c|c|c|}
\hline \multirow{2}{*}{ Nurses' Performance } & \multicolumn{2}{|c|}{ Done } & \multicolumn{2}{|c|}{ Not done } & \multirow{2}{*}{$\chi^{2}$} & \multirow{2}{*}{$p$} \\
\hline & no. & $\%$ & no. & $\%$ & & \\
\hline Assist the patient in setting position. & 26 & 43.3 & 34 & 56.7 & 1.1 & .302 \\
\hline Palpate the AVF for thrill after skin preparation. & 60 & 100 & 0 & 0 & 0 & 1 \\
\hline Extend the patient arm. & 60 & 100 & 0 & 0 & 0 & 1 \\
\hline Identify the inflow and outflow. & 57 & 95 & 3 & 5 & 48.6 & $<.001 *$ \\
\hline Pull the skin over the cannulation site. & 36 & 60 & 24 & 40 & 2.4 & .121 \\
\hline Initiate cannulation technique. & 60 & 100 & 0 & 0 & 0 & 1 \\
\hline Begin dialysis session. & 60 & 100 & 0 & 0 & 0 & 1 \\
\hline
\end{tabular}

* $p$-value was considered significant at .001 .

Table 3 shows that $96.7 \%$ of adolescents felt themselves in a more comfortable position when using the cushion cannulation technique compared to only $35 \%$ when using the common cannulation technique. The majority $(80 \%$ and $86.7 \%$ ) of adolescent mentioned that stabilization of arm and arm fully extended respectively when using the cushion cannulation technique compared with $46.7 \%$ and $21.7 \%$ when using the common cannulation technique. Also, $95 \%$ and $41.7 \%$ of adolescents mentioned that arm pulling back during cannulation is reduced when using the cushion cannulation technique as opposed to the common cannulation technique. More than half $(56.7 \%)$ of adolescent patients mentioned that the cushion cannulation technique is safer compared to $41.7 \%$ who preferred the common cannulation technique for safety. With the exception of safety, all other items displayed a statistical significant difference between the cushion and common cannulation techniques.

Table 4 illustrates that most nurses mentioned that using the cushion cannulation technique improves body mechanics $(98.3 \%)$, promotes easy access to fistula (96.7\%), stabilizes cannulator's hand (93.3\%) and makes easier the determination of the cannulation angle $(90 \%)$. The equivalent percentages of nurses using the common cannulation technique are $30 \%, 51.7 \%, 40 \%, 46.7 \%$ respectively indicating a statistical significant difference in each case $(p<.001)$.

Table 5 shows that $30 \%$ and $6.7 \%$ of adolescents had no pain when using the cushion and common cannulation techniques respectively, while moderate pain was found in $28.3 \%$ and $56.7 \%$ of adolescents during using cushion and common techniques respectively. Again a statistical significant difference is found between both cannulation techniques with regard to pain as measured by a numerical pain scale $(p<$ $.001)$.

Table 6 reports correlations between both cannulation techniques and the level of pain as measured by a numerical scale in which higher scores reflect greater pain. With regard to the cushion cannulation technique, statistically significant negative correlations were found between the level of pain and the stabilization of the arm, a fully extended arm and 
safety of the procedure. These findings indicate that better cedure. With regard to the common cannulation technique, stabilization of the arm, that holding the arm fully extended the equivalent correlations were positive, but not statistically and that improvements in the safety of the procedure all act significant. to reduce the pain experienced by adolescents during the pro-

Table 3. Percent distribution of adolescents according to their opinion about common versus cushion cannulation techniques (no. $=60$ )

\begin{tabular}{|c|c|c|c|c|c|c|}
\hline \multirow[t]{2}{*}{ Adolescents' Opinion } & \multicolumn{2}{|c|}{$\begin{array}{l}\text { Common cannulation } \\
\text { technique (Pretest) }\end{array}$} & \multicolumn{2}{|c|}{$\begin{array}{l}\text { Cushion cannulation } \\
\text { technique (Posttest) }\end{array}$} & \multirow[t]{2}{*}{$\chi^{2}$} & \multirow[t]{2}{*}{$p$} \\
\hline & no. & $\%$ & no. & $\%$ & & \\
\hline Position is more comfort. & 21 & 35 & 58 & 96.7 & 160.3 & $<.001^{*}$ \\
\hline Stabilization of arm. & 28 & 46.7 & 48 & 80 & 238.7 & $.003 *$ \\
\hline Arm fully extended. & 13 & 21.7 & 52 & 86.7 & 409.6 & $<.001 *$ \\
\hline Less arm pull back during cannulation. & 25 & 41.7 & 57 & 95 & 138.8 & $<.001^{*}$ \\
\hline More safe. & 25 & 41.7 & 34 & 56.7 & 15.2 & .222 \\
\hline
\end{tabular}

* $p$-value was considered significant at .001; Table represents yes answers only.

Table 4. Percent distribution of nurses according to their opinion about common versus cushion cannulation techniques (no. $=60)$

\begin{tabular}{|c|c|c|c|c|c|c|}
\hline \multirow[t]{2}{*}{ Nurses' Opinion } & \multicolumn{2}{|c|}{$\begin{array}{l}\text { Common cannulation } \\
\text { technique (Pretest) }\end{array}$} & \multicolumn{2}{|c|}{$\begin{array}{l}\text { Cushion cannulation } \\
\text { technique (Posttest) }\end{array}$} & \multirow[t]{2}{*}{$\chi^{2}$} & \multirow[t]{2}{*}{$p$} \\
\hline & no. & $\%$ & no. & $\%$ & & \\
\hline Improved body mechanics. & 18 & 30 & 59 & 98.3 & 94.9 & $<.001^{*}$ \\
\hline Easily access for fistula/graft. & 31 & 51.7 & 58 & 96.7 & 80.0 & $<.001^{*}$ \\
\hline Stability of the hand. & 24 & 40 & 56 & 93.3 & 88.1 & $<.001^{*}$ \\
\hline Less shadow from bending over access. & 16 & 26.7 & 47 & 78.3 & 105.2 & $<.001^{*}$ \\
\hline Proper eyes level during cannulation. & 27 & 45 & 48 & 80 & 115.2 & $.002 *$ \\
\hline Easy determination of cannulation angle. & 28 & 46.7 & 54 & 90 & 394.9 & $<.001^{*}$ \\
\hline
\end{tabular}

* $p$-value was considered significant at .001

Table 5. Percent distribution of adolescents according to numeric pain scale during common and cushion cannulation techniques (no. $=60$ )

\begin{tabular}{|c|c|c|c|c|c|c|}
\hline \multirow{2}{*}{ Numeric Pain Rating Scale } & \multicolumn{2}{|c|}{ Common cannulation technique } & \multicolumn{2}{|c|}{ Cushion cannulation technique } & \multirow{2}{*}{$\chi^{2}$} & \multirow{2}{*}{$p$} \\
\hline & no. & $\%$ & no. & $\%$ & & \\
\hline No pain & 4 & 6.7 & 18 & 30 & 17.78 & $<.001^{*}$ \\
\hline Mild pain & 20 & 33.3 & 25 & 41.7 & & \\
\hline Moderate pain & 34 & 56.7 & 17 & 28.3 & & \\
\hline Worst pain & 2 & 3.3 & 0 & 0 & & \\
\hline
\end{tabular}

$* p$-value was considered significant at .001 .

Table 6. Correlations between adolescents' opinion about both common cannulation, cushion cannulation techniques and Numeric pain scale

\begin{tabular}{|c|c|c|c|c|}
\hline \multirow[t]{2}{*}{ Adolescents' Opinions } & \multicolumn{2}{|c|}{$\begin{array}{l}\text { Numeric Pain Scale \& Common } \\
\text { cannulation technique }\end{array}$} & \multicolumn{2}{|c|}{$\begin{array}{l}\text { Numeric Pain Scale \& Cushion } \\
\text { cannulation technique }\end{array}$} \\
\hline & $r$ & $p$ & $r$ & $p$ \\
\hline Position is more comfortable. & .092 & .485 & $.118-$ & .371 \\
\hline Stabilization of arm and tissue. & .063 & .634 & $-.502-$ & $.000 * *$ \\
\hline Arm fully extended. & .223 & .087 & $-.330-$ & $.010^{*}$ \\
\hline Less arm pull back during cannulation. & .063 & .634 & $-.595-$ & .470 \\
\hline More safe. & .223 & .087 & $-.550-$ & $.000 * *$ \\
\hline
\end{tabular}

${ }^{*} p$-value was considered significant at .001 . 


\section{DiscuSsion}

Chronic hemodialysis (HD) is technically feasible in children of all ages. Although the principles of HD are similar for adults and children, there are technical aspects of the procedure and complications that are unique to the pediatric population. It is crucial that these differences are recognized and addressed in order to effectively and safely perform pediatric HD, thereby reducing complications and promoting an adolescent's quality of life. Provision of adequate vascular access remains the single greatest obstacle to successful HD; hence, good vascular access is one of the most important factors for successful hemodialysis Deborah (2011). ${ }^{[9]}$ Consequently, the aim of this study was to foster safe vascular access for adolescents during hemodialysis using cushion cannulation versus common cannulation techniques.

Concerning studied adolescents' age, the current study revealed that nearly two thirds of the adolescents were aged 18: $\leq 20$ years. The mean age of adolescents was $17.65 \pm$ 1.64 years. In the same context Hassan et al. (2012) ${ }^{[16]}$ who studied the impact of cryotherapy on pain intensity of puncture site of arterio-venous fistula among children undergoing hemodialysis and found that children age ranged between $12-16$ years and the mean age of them was $11.72 \pm 1.4$ years

The current study revealed that slightly more than half of the studied adolescents were male and the rest of them were female. This result was in agreement with Ahmed (2008) ${ }^{[17]}$ and Faheem et al. (2009) ${ }^{[18]}$ who found in similar study that more than half of the studied sample were male. These results were in contrast with the study of Hassan et al. (2012) $)^{[16]}$ and Mahmoud et al. (2009) ${ }^{[19]}$ who reported in similar study that more than half of the studied children were female.

On investigating adolescents' knowledge as regards arteriovenous access site safe, results of the current study indicated that all adolescents had correct knowledge about AV access safe in the form of: keeping the access site clean, not wearing clothes that restrict access to the site, not using the arm with AV fistula to carry heavy objects. Additionally, most of adolescents prevent anyone measuring blood pressure using arm with AV access site and not sleeping on this arm. Also, more than half of them had correct knowledge about monitoring the access site for signs of infection. These results may be due to adolescents acquiring experience about caring of $\mathrm{AV}$ access site because they had continuing regular dialysis sessions each week.

As regards nurses' performance during hemodialysis using the common cannulation technique, results of the current study revealed that slightly less than half of nurses assisted adolescents patients in the sitting position. Also, all nurses palpate AV fistula for thrill, extend patient's arm, initiate cannulation technique and begin dialysis session. Nearly two thirds of the nurses pull the skin over the cannulation site to the opposite direction. These results are in agreement with National kidney Foundation (2006), ${ }^{[20]}$ who mentioned that nurses must locate, inspect and palpate the needle cannulation site prior to skin preparation. Adherence to Hemodialysis Units' protocol of care for patients undergoing Hemodialysis helped the nurses in the current study to apply International Guidelines in Hemodialysis Units.

According to studied adolescents' opinion about the cushion cannulation versus the common cannulation techniques, results of the current study revealed that the majority of adolescents mentioned that stabilization of the arm and their arm were fully extended when using the cushion cannulation technique. These results were supported by Stuart $(2006),{ }^{[21]}$ who applied the cushion cannulation technique and confirmed that stabilization of the patient arm and tissue, with the arm fully extended on cushion and also the patient ability to pull back the arm during cannulation is limited.

In relation to the participant nurses' opinion about the cushion and the common cannulation techniques, results of the present study showed that most of nurses reported that using the cushion technique improves body mechanics, promotes ease of access to fistula site, stabilizes cannulator's hands and assists in determination of the cannulation angle. These results may be attributed to that stability for the cannulator's hands, forearm, and the horizontal plane of the access arm and height just below the cannulator's eye level help facilitating determination of the angle of cannulation. These results are in accordance with the result of Stuart (2006), ${ }^{[21]}$ who emphasized that the cannulator's body mechanics are improved both by the seated position and also having the access site at the same level as the cannulator's hands and forearms.

Regarding assessment of adolescents level of pain during cushion and common cannulation techniques using numeric pain severity scale, results of the current study illustrated that more than half of adolescents had moderate pain using common cannulation technique compared to approximately one quarter of them who experienced moderate pain during the cushion technique. Also, the cushion technique was associated with no pain as reported by one third of adolescents compared to the minority of them using the common cannulation technique. These findings stressed that using the cushion cannulation technique was linked to decreased pain sensation during arterio-venous access site.

These findings were in congruent with Eglence et al. (2013) ${ }^{[22]}$ who utilized pain control behaviors by using techniques of positioning, rubbing and splinting to limit pain. 
Findings of the current study were in congruent with the study of Hassan et al. (2012), ${ }^{[16]}$ who reported that more than one thirds of children in the control group had moderate or mild pain during artery needle puncture, while less than half of them had mild or no pain.

In this context, Hassan et al. (2012) ${ }^{[16]}$ were found that, the mean of pain scale were reduced in the study group than the control group. Findings of the current study were also in agreement with the study of Celik et al. $(2011)^{[23]}$ and Nikki et al. (2013), ${ }^{[24]}$ who reported that pain score reduced during artery and vein needle puncture in the study group.

On investigating correlations between the level of pain as measured by a numerical pain scale and the cushion cannulation technique, findings of the current study revealed that there was a negative correlation between stabilization of arm and level of pain. These results explained that better stabilization of the arm, that holding the arm fully extended and that improvements in the safety of the procedures all act to reduce the pain experienced by adolescents during the procedure using the cushion cannulation technique. These findings were in agreement with the study of Ball (2006), ${ }^{[14]}$ who studied the button technique for arterio-venous fistula cannulation, and reported that cushion cannulation promotes consistent arm position, stabilization and decreased level of pain.

In this context, Brower (2005) ${ }^{[8]}$ and Isabella et al. (2014), ${ }^{[25]}$ who examined needle placement to achieving effective dialysis and preserving vascular access and reported that patients arm supported by the arm of the chair on cushion allows better visualization, stabilization of arm and tissues, as well as patients feel more comfort.

\section{Conclusion}

The current study concluded that using the cushion technique was associated with safe vascular access site for adolescents during hemodialysis. The majority of the adolescents mentioned, stabilization of arm, arm fully extended and also little arm pulling back during cannulation when using the cushion technique as opposed to the common cannulation techniques. Most of the participants nurses mentioned that using the cushion technique improves body mechanics, promotes ease of access to fistula, stabilizes cannulator's hand and ease of the determination of the cannulation angle. As well as statistically significant negative correlations were found between safe vascular access site using the cushion technique and the level of pain, which explained the fact that with using the cushion technique was associated with reduced pain experienced by adolescents during the procedures. With regard to the common cannulation technique, the equivalent correlations were positive, but not statistically significant.

\section{Recommendations}

Application of cushion technique in HD units as a part of a routine care for all patients undergoing hemodialysis therapy. Implement in-service training programs related to the cushion technique for all nurses working in Hemodialysis Units. Further studies are needed to examine the effect of the cushion technique to promote safety vascular access cannulation. Replication of the study in larger probability sample in a different hospitals at Saudi Arabia.

\section{CONFLiCTS OF INTEREST Disclosure}

The authors declare that there is no conflict of interest.

\section{REFERENCES}

[1] Shaheen A, Al-khadera A. Preventive strategies of renal failure in the Arab World Kidney Int. 2005; 98: 537-540.

[2] Thash Kandy A, Gazzaz J, Dhafar O. An audit of end stage renal disease in a tertiary care hospital. Archives of Hellenic Medicine. 2012; 29(2): 207-211.

[3] Al-Sayyari A. End stage chronic disease in Saudi Arabia. Saudi Med J. 2011; 32(4): 339-346

[4] Gorman G. Hospitalization rates and clinical performance measures in U.S. adolescent hemodialysis patients. Journal of International Pediatric Nephrology Association. 2010; 25(11): 2335-2341. https ://doi.org/10.1007/s00467-010-1597-8

[5] Schroeder I. Children and adolescents on hemodialysis: attributes associated with quality of life. USP. 2014; 48(4): 602-609.

[6] Ponikvar R, Buturovic J. Temporary hemodialysis catheters as a long-term vascular access in chronic hemodialysis patients. Thera- peutic Apheresis and Dialysis. 2005; 9: 250-253. PMid:15967000 https://doi.org/10.1111/j.1774-9987.2005.00265.x

[7] Arenas D, Sanchez-Paya J, Barril G. A multicentric survey of the practice of hand hygiene in haemodialysis units: Factors affecting compliance. Nephrol Dial Transplant. 2005; 20: 1164-1171. PMid:15769816 https : //doi.org/10.1093/ndt/gfh759

[8] Brower D. Needle placement is paramount to achieving effective dialysis and preserving vascular accesses. Nephrology Nursing Journal. 2005; 32(2): 225-227.

[9] Deborah J. Cannulation Camp: Basic Needle Cannulation Training for Dialysis Staff. Dialysis \& Transplantation. 2011. Available from: http://rsaannualconference.org.au

[10] Berman S. Vascular access in clinical practice. New York: Marcel Dekker, Inc. 2002. https : //doi .org/10.3109/9780203908860

[11] Ball L. Improving arterio-venous fistula cannulation skills. Nephrology Nursing Journal. 2005; 32(6): 611-617. PMid:16425809 
[12] Mott S, Prowant B. The "cushion cannulation" technique. Nephrology Nursing Journal. 2006; 33(6): 683-684. PMid:17219730

[13] Gulati S, Lall N. Hemodialysis in Children. JIMSA. 2012; 25(2): 101-105.

[14] Ball L. The buttonhole technique for arteriovenous fistula cannulation. Nephrology Nursing Journal. 2006; 33(3): 299-304. PMid:16859201

[15] Galer J, Gammaitoni A. Pain assessment in clinical trials. In D. Carr \& H. Wittink (Eds.), Evidence, outcomes, and quality of life in pain treatment. Amsterdam: Elsevier. Nursing Journal. 2003; 32(2): $225-$ 227.

[16] Hassan M, Darwish M, Elsamman A, et al. The impact of cryotherapyon pain intensity at puncture sites of arterio-venous fistula among children undergoing hemodialysis. Journal of American Science. 2012; 8(12). http://www . jof americanscience.org

[17] Ahmed AS. Stressors as perceived by children undergoing hemodialysis, Unpublished Master Thesis, Faculty of Ng., Alex. University. 2008.

[18] Faheem MS, El Sayed HM, El Sayed SS, et al. Circulating endothelial cells as a marker of the state of endothelium in children under regular hemodialysis therapy. The Egyptian Society for Pediatric Nephrology and Transplantation. 2009; 9(2): 65-85.

[19] Mahmoud S, Shoulah S, Al-Sharkawi S, et al. Needs Assessment of Children Undergoing Hemodialysis Therapy. The New Egyptian Journal of Medicine. 2009; 40(2): 150-159.
[20] National Kidney Foundation. KDOQI Clinical Practice Guidelines and Clinical Practice Recommendations, Hemodialysis Adequacy, Peritoneal Dialysis Adequacy and Vascular Access. Am J Kid Dis. 2006; 48: S1-S322. Available from: http://www.Kidney.org./ professiona/Kdoqi/guidlinesup

[21] Stuart B. The "Cushion Cannulation" Technique, Nephrology. Nursing Journal. 2006; 33(6).

[22] Eglence R, Karatas N, Tasci S. The effect of acupressure on the level of fatigue in hemodialysis patients. Altern there health Med. 2013; 19(6): 23-31.

[23] Celik G, Ozbek O, Yilmaz M, et al. Vapocooland spray vslidocaine cream for reducing the pain of veinpuncture in hemodialysis patients: A randomized placebo-controlled, crossover study. International Journal of Medical Science. 2011; 8: 623-627. https : //doi.org/10.7150/ijms.8.623

[24] Nikki J, Schoenmaker F, Tromp H, et al. Quality and Consistency of Clinical Practice Guidelines for the Management of Children on Chronic Dialysis. Nephrol Dial Transplant. 2013; 28(12): 3052-3061. PMid:24097802 https : //doi.org/10.1093/ndt/gft303

[25] Isabella A, Maria K, Danielle S, et al. Children and adolescents on hemodialysis: attributes associated with quality of life. USP. 2014; 48(4). 